\title{
Subject Biomarker Supplemental Qualifiers Dataset
}

National Cancer Institute

\section{Source}

National Cancer Institute. Subject Biomarker Supplemental Qualifiers Dataset. NCI

Thesaurus. Code C147245.

A dataset containing supplemental information, specifically non-standard variables, to parent records in the subject biomarker domain. 